\title{
Immediate early response of the circadian polyA ribonuclease nocturnin to two extracellular stimuli
}

\author{
EDUARDO GARBARINO-PICO, ${ }^{1}$ SHUANG NIU, ${ }^{1}$ MARK D. ROLLAG, ${ }^{2,3}$ CARL A. STRAYER, ${ }^{1,4}$ \\ JOSEPH C. BESHARSE, ${ }^{2}$ and CARLA B. GREEN ${ }^{1}$ \\ ${ }^{1}$ Department of Biology, University of Virginia, Charlottesville, Virginia 22904, USA \\ ${ }^{2}$ Department of Cell Biology, Neurobiology, and Anatomy, Medical College of Wisconsin, Milwaukee, Wisconsin 53226, USA
}

\begin{abstract}
Nocturnin (Noc, also called Ccrn4I [carbon catabolite repression 4-like]) is a circadian deadenylase that is rhythmically expressed in multiple tissues in mice with peak mRNA levels in early night. Since several other circadian genes are induced by extracellular stimuli, we tested the hypothesis that Noc is acutely regulated in NIH3T3 cells. A serum shock and the phorbol ester TPA induced Noc transcript levels in quiescent NIH3T3 cultures while dexamethasone and forskolin, which are known to induce other clock genes in culture, were without effect. NOC protein levels also were induced by serum. The half-life of the TPA-induced Noc mRNA is short, and the inhibition of protein synthesis by cycloheximide prevents Noc mRNA degradation and revealed a 30-fold increase in the transcript levels after $4 \mathrm{~h}$ of TPA treatment. Since this acute induction is not dependent on protein synthesis, Noc behaves like other immediate early genes. Remarkably, these acute effects are specific to Noc as the mRNAs encoding other known mouse deadenylases, CCR4, CAF1, PAN2, and PARN, were not induced in the same paradigm. Our data show that in addition to its robust circadian regulation, Noc expression can be regulated acutely, and imply that it can respond directly and specifically to physiological cues. NOC may act in turning off the expression of genes that are required to be silenced as a response to these extracellular signals.
\end{abstract}

Keywords: Nocturnin; deadenylase; mRNA decay; induction; circadian rhythms; immediate early gene (IEG)

\section{INTRODUCTION}

Mammalian cells modulate their gene expression in response to extracellular signals. These stimuli induce changes in transcriptional processes modifying the expression of genetic networks. However, post-transcriptional events also play an important role, with regulation of mRNA decay providing an additional critical regulatory step. The half-lives of numerous mRNAs change markedly in response to external cues; the control of this process provides the cell with more flexibility to adjust its physiology (Wilusz et al. 2001; Shim and Karin 2002; Wilusz and Wilusz 2004). Although the mechanism by which different factors activate signaling cascades that in turn induce changes in transcription programs has been extensively

Present addresses: ${ }^{3}$ Department of Biology, University of Virginia, Charlottesville, VA 22904, USA. ${ }^{4}$ Promega, 2800 Woods Hollow Road, Madison, WI 53711, USA.

Reprint requests to: Carla B. Green, Department of Biology, University of Virginia, 275 Gilmer Hall, P.O. Box 400328, Charlottesville, VA 229044328, USA; e-mail: cbg8b@virginia.edu; fax: (434) 982-5626.

Article published online ahead of print. Article and publication date are at http://www.rnajournal.org/cgi/doi/10.1261/rna.286507. studied, much less is known about how external stimuli regulate mRNA stability.

In eukaryotic cells, the major mRNA decay pathways begin with the shortening of the polyA tail at the $3^{\prime}$ end of the transcripts, followed by degradation either by decapping and $5^{\prime} \rightarrow 3^{\prime}$ exonucleolytic digestion, or alternatively by $3^{\prime} \rightarrow 5^{\prime}$ exonuclease decay (for review, see Wilusz et al. 2001; Parker and Song 2004). The removal of polyA tails, thought to be the rate-limiting and more-regulated step in mRNA decay (Cao and Parker 2001; Wang et al. 2002), is carried out by a class of ribonucleases called deadenylases.

Nocturnin (Noc; also known as Corn4l) is a deadenylase that was originally identified in a screen for circadian clockregulated genes in Xenopus retina (Green and Besharse 1996a); it was subsequently shown to be a $\mathrm{Mg}^{2+}$-dependent polyA-specific exoribonuclease (Baggs and Green 2003). Noc mRNA levels oscillate, peaking at night in both Xenopus (Green and Besharse 1996a; Liu and Green 2002) and mouse (Wang et al. 2001; Barbot et al. 2002).

Circadian rhythms are biological variables displaying $\sim 24 \mathrm{~h}$ cycles even in the absence of external cues. These oscillations are endogenously controlled, genetically determined, ubiquitous, and observed at molecular, physiological, behavioral, and even population levels (for review, 
see Reppert and Weaver 2002; Lowrey and Takahashi 2004). The circadian system provides organisms with a temporal organization and allows them to predict environmental cyclic changes and adapt their physiology accordingly (Pittendrigh 1993). Circadian clocks are intracellular mechanisms present in many cells and tissues throughout the body. For example, mammalian fibroblasts contain functional clocks that drive circadian rhythms in gene expression (Balsalobre et al. 1998; Nagoshi et al. 2004; Welsh et al. 2004) and metabolism (Marquez et al. 2004). These oscillations can be observed in vitro after the synchronization of the cell population by a serum shock or other stimuli. Fibroblast cultures have emerged as an excellent model to study cellular clocks and their interaction with physiological signals (Nagoshi et al. 2005).

In this study we investigated, in NIH3T3 cultures, the response of mouse Noc ( $m N o c)$ to different extracellular stimuli that entrain circadian clocks and affect the stability of many mRNAs. We found that $m N o c$ expression was induced by serum and the phorbol ester TPA. This acute induction was observed even in the presence of protein synthesis inhibitors, indicating that $m N o c$ is an immediate early gene (IEG). Remarkably, $m N o c$ was the unique deadenylase induced by serum shock among the five polyAspecific ribonucleases described thus far in mouse. Our results suggest that mNOC plays a role in turning off the expression of genes that are silenced under this paradigm.

\section{RESULTS}

\section{mNOC is a deadenylase}

The $\mathrm{C}$ terminus of Xenopus NOC (xNOC) and its mouse ortholog has strong sequence similarity with the $\mathrm{C}$ terminus of yeast CCR4 (Green and Besharse 1996a; Dupressoir et al. 1999, 2001; Wang et al. 2001). This is the catalytic domain responsible for the deadenylase activity of yCCR4 and because of this, $m$ Noc is also known as Ccrn 4 l (carbon catabolite repression 4-like).

We have previously shown that $\mathrm{xNOC}$ is a $\mathrm{Mg}^{2+}$ dependent polyA-specific exoribonuclease (Baggs and Green 2003). We sought to verify that mNOC also displays deadenylase activity (Fig. 1). Recombinant GST-tagged mNOC (GST-mNOC) was incubated with a synthetic $\left({ }^{32} \mathrm{P}\right)$-RNA substrate (body of 86 nucleotides [nt] of the $\beta$-globin 3' UTR, and polyA tail of $100 \mathrm{nt}$ ) in the presence of $\mathrm{Mg}^{2+}$ and buffer. Xenopus polyA-specific ribonuclease with a C-terminal His-tag (xPARN-His) was assayed as a positive control (Copeland and Wormington 2001; Baggs and Green 2003). In addition to the enzyme blank, we included three different negative controls: mouse CRY2, the protein product of a clock gene unrelated to nucleases; a predicted $\mathrm{Mg}^{2+}$-binding mutant; and $\mathrm{mNOC}$ plus the divalent ion chelator EDTA. In the $\mathrm{Mg}^{2+}$-binding mutant protein we replaced the glutamic acid at position 193 with

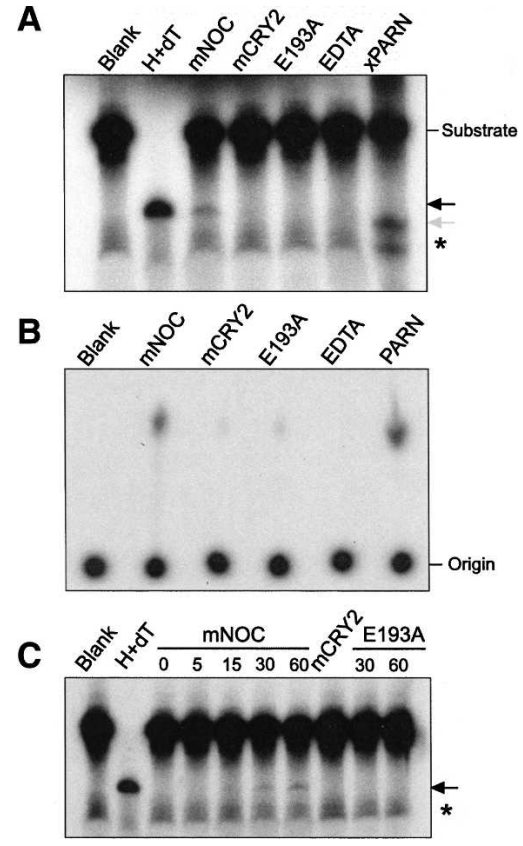

FIGURE 1. mNOC is a processive deadenylase. $(A)$ Autoradiography showing the products of an in vitro deadenylase assay separated by electrophoresis in a polyacrylamide/urea gel. The synthetic RNA substrate (body, $86 \mathrm{nt}$; polyA tail, $100 \mathrm{nt} ; 1 \times 10^{5} \mathrm{dpm}, \sim 1.5 \mathrm{ng}$ ) was labeled with $\left(\alpha-{ }^{32} \mathrm{P}\right)$-UTP and incubated for $30 \mathrm{~min}$ with different proteins $\left(500 \mathrm{ng}\right.$ ) in the presence of buffer and $\mathrm{Mg}^{2+}$. (B) Autoradiography showing the products of a deadenylase assay where the substrate was transcribed in the presence of $\left(\alpha-{ }^{32} \mathrm{P}\right)$-ATP (both tail and body were radiolabeled) and resolved by TLC. $(C)$ Deadenylation assay (as in $A$ ) showing the product accumulation over time (minutes indicated on the top). The experiments shown are representative of $\mathrm{n}=4$ in $A, \mathrm{n}=1$ in $B$, and $\mathrm{n}=2$ in $C$. (Blank) No protein control, $(\mathrm{H}+\mathrm{dT})$ the substrate was incubated with RNase $\mathrm{H}$ in the presence of oligo(dT) to generate a deadenylated marker, (mNOC) GST-mNOC, (mCRY2) GST-mCRY2, (E193A) predicted GST-mNOC $\mathrm{Mg}^{2+}$-binding mutant, (EDTA) $25 \mathrm{mM}$ EDTA, and GST-mNOC were added at the beginning of the reaction, $(\mathrm{xPARN}) \mathrm{xPARN}-\mathrm{His}$. Note that while the GST-tagged proteins were incubated linked to sepharose beads, PARN-His was added in solution. (Black arrow) Mobility of the deadenylated product, (gray arrow) a PARN activity product (this enzyme, in addition to the polyA tail, trims a few nucleotides into the body), and (asterisk) nonspecific band present in all lanes.

an alanine (E193A in the mNOC sequence). This is a conserved $\mathrm{Mg}^{2+}$-binding residue in the CCR4, DNase I, APE1, and IP5P family (Dlakic 2000; Dupressoir et al. 2001). It has been shown before that this mutation impairs deadenylase activity in yCCR4 (Chen et al. 2002) and xNOC (Baggs and Green 2003). The radiolabeled substrate and products were separated by polyacrylamide gel electrophoresis (Fig. 1A) or thin layer chromatography (TLC; Fig. 1B) and detected by autoradiography as described previously (Copeland and Wormington 2001; Baggs and Green 2003).

The deadenylase assay (Fig. 1A) showed that GSTmNOC generated an RNA product with identical electrophoretic mobility to the deadenylated marker. This band 
was not observed in the enzyme blank or the three negative controls. The mNOC product runs slightly larger than the product generated by xPARN-His, which has been shown to remove nucleotides slightly beyond the polyA tract (Copeland and Wormington 2001; Baggs and Green 2003). This was also previously observed with xNOC (Baggs and Green 2003). The fraction of substrate deadenylated by GST-mNOC was consistently lower than that obtained with xPARN-His. The TLC analysis (Fig. 1B) showed a product of GST-mNOC activity with mobility indistinguishable from the 5'-AMP observed in the xPARN-His lane (Copeland and Wormington 2001). This product is nearly undetectable in the GST-CRY2 and the GST-mNOC $\mathrm{Mg}^{2+}$-binding mutant lanes. We tested whether longer incubation times would produce full deadenylation of the substrate (Fig. 1C). Deadenylated product was not detectable after $5 \mathrm{~min}$ of incubation, but became visible after $15 \mathrm{~min}$ and continued to increase over time. However, even after $1 \mathrm{~h}$, the fraction of nondeadenylated substrate is still high. Therefore, mNOC has specific polyA exonuclease activity, but this activity is not robust in vitro.

\section{$m$ Noc expression is acutely induced in quiescent NIH3T3 cells by serum shock and TPA}

Mammalian fibroblasts contain functional clocks that sustain circadian rhythms in culture (Balsalobre et al. 1998; for review, see Nagoshi et al. 2005). Despite the fact that individual cells exhibit ongoing circadian rhythms (Nagoshi et al. 2004; Welsh et al. 2004), in order to be able to measure oscillations in a cell population the culture must be synchronized with an external cue. A serum shock (Balsalobre et al. 1998; Nagoshi et al. 2004), the phorbol ester TPA (Akashi and Nishida 2000), forskolin (Balsalobre et al. 2000; Yagita and Okamura 2000), and dexamethasone (Balsalobre et al. 2000) are factors capable of synchronizing fibroblast clocks in culture.

Because $m N o c$ is a circadian clock controlled gene, we examined its expression in rhythmic NIH3T3 cultures, which provide a valuable in vitro model system. In doing so we found that $m N o c$ expression was acutely induced by some of the entrainment stimuli. Confluent NIH3T3 cultures were maintained for $2 \mathrm{~d}$ in 1\% FBS-DMEM; thus, cells were quiescent and serum-starved before the stimulation. When fibroblasts were treated with $100 \mathrm{nM}$ TPA, a rapid increase in the $m N o c$ mRNA levels was observed, with about eightfold higher levels after $1 \mathrm{~h}$ (Fig. 2A). To check whether this treatment induced clock gene expression, the mRNA levels of mPerl were also analyzed. As expected, TPA increased the relative quantities of this transcript to an extent similar to that previously reported (Akashi and Nishida 2000). A serum shock (50\% FBS-DMEM) also induced $m N o c$, again with maximal values about eightfold higher compared with untreated cells and with a temporal profile similar to TPA (Fig. 2B). In both cases the maximal
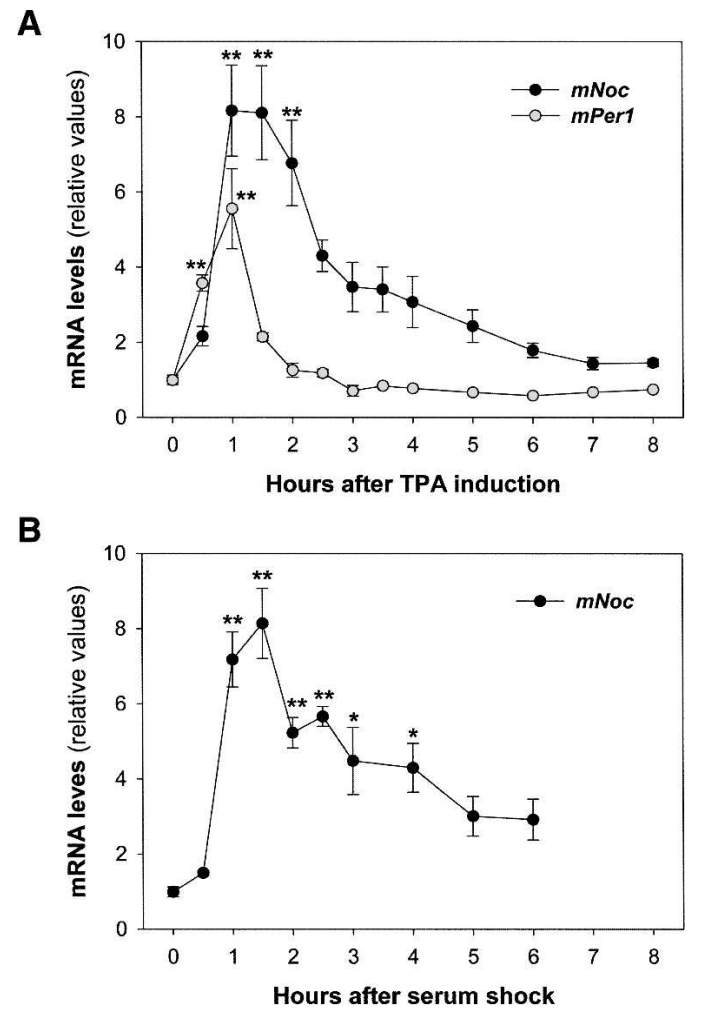

FIGURE 2. Acute induction of $m N o c$ in NIH3T3 cultures. $100 \mathrm{nM}$ TPA $(A)$ or $50 \%$ FBS-DMEM $(B)$ produced approximately an eightfold increment in $m N o c$ mRNA levels in quiescent and serum-starved cells. TPA also induced the clock gene mPer1. Confluent cultures were maintained for $2 \mathrm{~d}$ in 1\% FBS-DMEM before the treatment. Relative transcript levels were determined by Northern blot, quantified by densitometry, and normalized by rRNA content. Values represent the mean \pm SEM of three independent experiments in $A(n=8-9 /$ group, $\mathrm{F}=10.4, p=1.3 \mathrm{E}-12$ by ANOVA $)$ and two in $B(\mathrm{n}=5 /$ group, $\mathrm{F}=15.4, p=1.8 \mathrm{E}-10$ by ANOVA). $\left({ }^{*}\right) p<0.01,\left({ }^{* *}\right) p<0.001$ by post hoc comparisons.

increases were observed during the first hour post-stimulation, and after $1.5 \mathrm{~h}$ mRNA levels begin to decline. Note that while TPA remained in the medium throughout the experiment, serum was replaced after $2 \mathrm{~h}$ by $1 \%$ FBSDMEM. We also tested the effect of a 15 min TPA pulse, and the results were similar to those obtained with the chronic treatment (data not shown). In contrast with these agents, a $15 \mathrm{~min}$ treatment with $10 \mu \mathrm{M}$ forskolin or $100 \mathrm{nM}$ dexamethasone did not increase $m N o c$ message levels (data not shown).

\section{$m$ Noc is an immediate early gene (IEG)}

Rapid induction is a signature of IEGs, and the mNocstimulation curves resemble an IEG-like response. As is stated in their name, IEGs are involved in the first stage of the cellular response to a stimulus, and by definition their induction does not require new protein synthesis. To determine whether $m N o c$ is an IEG, we analyzed the effect of protein synthesis inhibition on the TPA induction of $m$ Noc. 
Cycloheximide (CHX) was added to the cultures $1 \mathrm{~h}$ before the stimulation and maintained throughout the experiment. Figure 3 shows that this treatment did not abolish the TPA mNoc induction. Moreover, the increment in mRNA levels was threefold larger than the control (25fold versus eightfold comparing $\mathrm{T}=0$ with the peak). During the first hour the mRNA accumulation rates were similar. However, in CHX-treated cells the levels increased continually for $3.5 \mathrm{~h}$, whereas the control began to decline after $\sim 1.5 \mathrm{~h}$. Since the acute induction by an extracellular signal does not require de novo protein synthesis, we conclude that $m N o c$ is an IEG.

\section{$m$ Noc transcript has a short half-life and is stabilized by protein synthesis inhibition}

To characterize the transient induction of $m N o c$, we determined the half-life of the TPA-induced transcript when its levels were highest. We treated NIH3T3 cells with TPA as in Figures 2 and 3 . After $2 \mathrm{~h}$, transcription was inhibited with the addition of actinomycin $\mathrm{D}$ to the culture medium, and the cells were harvested at different times after the treatment. The mRNA decay rate was determined by Northern blot. Figure 4A shows a representative Northern blot, and Figure $4 \mathrm{~B}$ shows the graph obtained by the quantification of four such experiments. The half-life of the $m N o c$ message induced after $2 \mathrm{~h}$ of TPA induction was $\sim 50 \mathrm{~min}$.

Subsequently, we asked whether the CHX treatment has an effect on the $m N o c$ transcript stability. We utilized the same experimental scheme described above to determine mRNA half-life, but adding CHX $1 \mathrm{~h}$ before stimulation of the cultures (as had been done in Fig. 3). Inhibition of

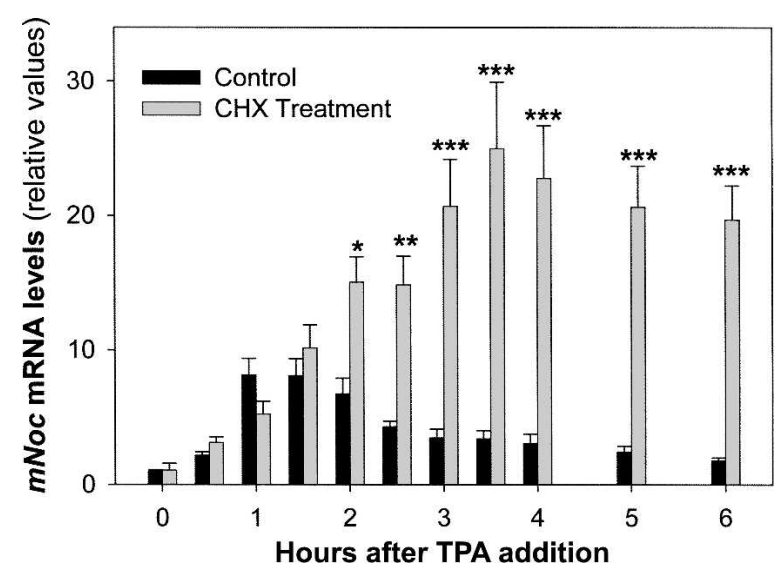

FIGURE 3. $m N o c$ is an immediate early gene (IEG). Quiescent and serum-starved NIH3T3 cells were treated with $10 \mu \mathrm{M}$ cycloheximide (CHX) $1 \mathrm{~h}$ before induction of $m N o c$ with $100 \mathrm{nM}$ TPA as was described in Fig. 2. This treatment showed that TPA acute induction is independent of protein synthesis; thus, $m N o c$ is an IEG. Results are the mean \pm SEM of three independent experiments by triplicate ( $\mathrm{n}=9$ /group). The effect of the CHX was statistically significant $(\mathrm{F}=145, p=9.11 \mathrm{E}-25$ by ANOVA $\left.) .\left(^{*}\right) p<0.05,{ }^{* *}\right) p<0.01$, $\left.{ }^{\star * *}\right) p<0.001$ by post hoc comparisons.

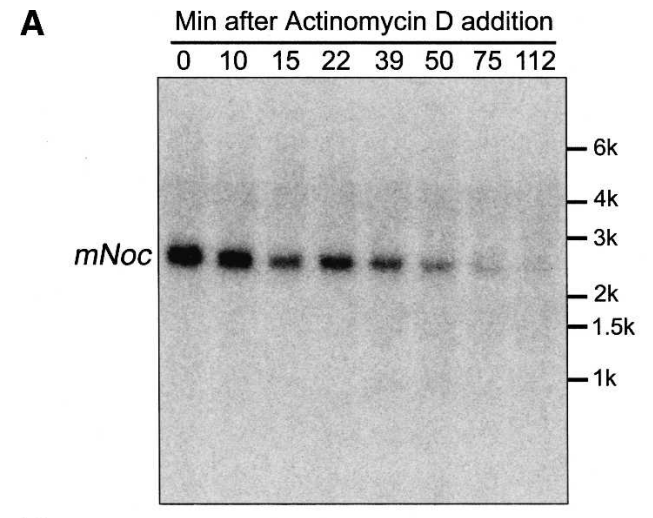

B

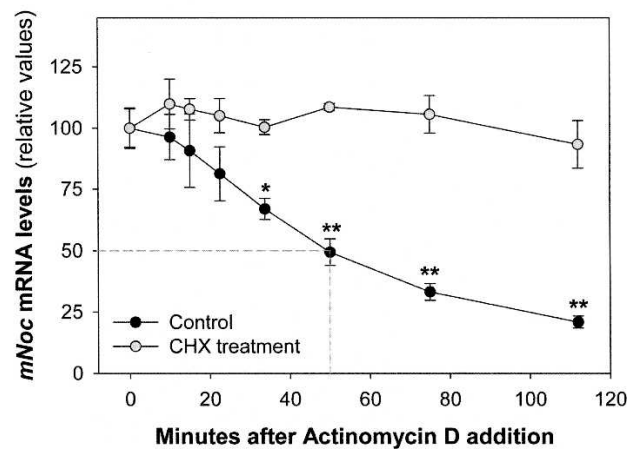

FIGURE 4. $m$ Noc-induced transcript has a short half-life and is stabilized by cycloheximide. (A) Northern blot showing the $m \mathrm{Noc}$ mRNA levels after actinomycin D addition. Quiescent NIH3T3 cells were TPA stimulated as in Fig 2; after $2 \mathrm{~h}$, transcription was inhibited by the addition of actinomycin D. (B) Quantification of the transcript decay rate and effect of $\mathrm{CHX}$ on $m$ Noc mRNA half-life. Control NIH3T3 cultures were processed as in A; CHX-treated cells received $10 \mu \mathrm{M}$ of this translation inhibitor $1 \mathrm{~h}$ before TPA stimulation. Values are the mean $\pm \operatorname{SEM}(\mathrm{n}=4$ /group). $m$ Noc mRNA half-life was estimated to be $\sim 50 \mathrm{~min}$ (dotted line). The effect of the CHX on mRNA half-life was statistically significant $(\mathrm{F}=123.00 ; p=7.68 \mathrm{E}-15$ by ANOVA). $\left(^{*}\right) p<0.05,\left({ }^{* *}\right) p<0.001$ by post hoc comparisons.

protein synthesis had a protective effect on the $m N o c$ message induced by TPA stimulation (Fig. 4B). Thus, the "superinduction" of $m N o c$ shown in Figure 3 is, at least in part, caused by transcript stabilization.

\section{$m$ Noc is the unique deadenylase induced in serum-stimulated NIH3T3 cells}

The cellular response to extracellular stimuli includes the transcriptional activation of several genes, but also the silencing of others. Moreover, many genes involved in the early response are induced only transiently. In order to turn off the expression of these genes, transcription must be discontinued, but it is also necessary to degrade their mRNAs. Since mNOC is part of this early response, we hypothesized that it could be involved in the degradation of these transcripts. However, there are other known deadenylases that may also participate in this response. To try to elucidate this point, we measured the mRNA levels of 
the other known mouse deadenylases during this acute induction paradigm.

These determinations were done by real-time RT-PCR. The accurate normalization of the data obtained with this method is an important issue since the expression of housekeeping genes can vary considerably in different cells and circumstances (Vandesompele et al. 2002). We measured, in our specific experimental conditions, five potential internal control RNAs: $18 S$ rRNA, GAPDH, HRPT1, $T B P$, and $\beta 2 M$ (see Table 1 for complete names and GenBank accession numbers). To determine the expression regularity of these genes on the basis of nonnormalized data, we applied the principle that the expression ratio of two or more ideal internal control genes should be identical in all samples (Vandesompele et al. 2002). Figure 5A shows the relative RNA values of these genes at different time points after a serum shock. The data are expressed as fold changes compared with nonstimulated cells $(\mathrm{T}=0)$. The RNA profiles obtained for $18 S r R N A, T B P$, and $\beta 2 M$ were similar and did not show significant changes after the stimulation. This is consistent with the report by Schmittgen and Zakrajsek (2000), who showed that $\beta 2 M$ and $18 S$ $r R N A$, but not $G A P D H$, follow the same profile as total mRNA in serum-stimulated NIH3T3 cells. We selected $\beta 2 M$ for data normalization because it showed less variation than $T B P$, and its levels are more similar to specific mRNAs as compared with the highly abundant $18 S \mathrm{rRNA}$.

We examined the relative mRNA values of five polyAspecific ribonucleases or catalytic subunits of deadenylase complexes: Noc (Fig. 1; Baggs and Green 2003), CCR4 (Dupressoir et al. 2001; Chen et al. 2002), CAF1 (Viswanathan et al. 2004), PARN (Korner and Wahle 1997; Korner et al. 1998), and PAN2 (Uchida et al. 2004) (see Table 1 for full names and GenBank accession numbers). To our knowledge, this includes all the currently identified mouse deadenylases (for review, see Parker and Song 2004).

Figure $5 \mathrm{~B}$ shows clearly that the only deadenylase mRNA induced by serum shock is mNoc. The magnitude of the mRNA level increase was exceptionally high ( $~ 30$-fold $)$ in this experiment, in contrast to eightfold seen in Figure 2. This variation probably reflects differences in experimental design and the use of RT-PCR rather than Northern blot for quantification. The data in Figure 2 involved starvation in 1\% FBS and stimulation with 50\% FBS followed by Northern blot analysis, while those in Figure 5 involved starvation in $0.5 \%$ FBS and stimulation with 50\% horse serum followed by real-time RT-PCR analysis. In addition, when cultures were not serum deprived (maintained in $10 \%$ FBS before the stimulation), the horse serum induction observed was about sevenfold (data not shown),

TABLE 1. Primer sequences for real-time RT-PCR

\begin{tabular}{|c|c|c|c|c|}
\hline \multirow[b]{2}{*}{ Abbreviation } & \multirow[b]{2}{*}{ Names } & \multirow[b]{2}{*}{ Accession number } & Forward primer & \multirow[b]{2}{*}{ Amplicon size } \\
\hline & & & Reverse primer & \\
\hline $18 S$ rRNA & $18 S$ ribosomal $R N A$ & X00686 & $\begin{array}{l}\text { CGCCGCTAGAGGTGAAATTC }^{\mathbf{a}} \\
\text { CGAACCTCCGACTTTCGTTCT }\end{array}$ & $101 \mathrm{nt}$ \\
\hline$\beta 2 M$ & $\beta 2-$ Microglobulin & NM_009735 & $\begin{array}{l}\text { TTCTGGTGCTTGTCTCACTGA } \\
\text { CAGTATGTTCGGCTTCCСATTC }\end{array}$ & $104 \mathrm{nt}$ \\
\hline CAF1 & $\begin{array}{l}\text { CAF1 (POP2 homolog), CCR4-NOT } \\
\text { complex subunit } 7\end{array}$ & NM_011135 & $\begin{array}{l}\text { CAGCAACCGTAGATCATAGCC } \\
\text { CTCGGTGTCCATAGCAACATAAT }\end{array}$ & $119 \mathrm{nt}$ \\
\hline CCR4 & CCR4, CCR4-NOT complex subunit 6 & NM_212484 & $\begin{array}{l}\text { ATCCAGAGTTTACCGGCAGAA }{ }^{\mathbf{b}} \\
\text { GTTTTCCCAGCTCAAAAGGTAGA }\end{array}$ & $100 \mathrm{nt}$ \\
\hline GAPDH & $\begin{array}{l}\text { Glyceraldehyde-3-phosphate } \\
\text { dehydrogenase }\end{array}$ & NM_001001303 & $\begin{array}{l}\text { AGGTCGGTGTGAACGGATTTG } \\
\text { TGTAGACCATGTAGTTGAGGTCA }\end{array}$ & $123 \mathrm{nt}$ \\
\hline HPRT1 & $\begin{array}{l}\text { Hypoxanthine guanine phosphoribosyl } \\
\text { transferase } 1\end{array}$ & NM_013556 & $\begin{array}{l}\text { TCAGTCAACGGGGGACATAAA } \\
\text { GGGGCTGTACTGCTTAACCAG }\end{array}$ & $142 \mathrm{nt}$ \\
\hline$m \mathrm{Noc}$ & Nocturnin, CCRN4L & AF199491, NM_009834 & $\begin{array}{l}\text { ACCAGCCAGACATACTGTGC } \\
\text { CTTGGGGAAAAACGTGCCT }\end{array}$ & $101 \mathrm{nt}$ \\
\hline PAN2 & $\begin{array}{l}\text { PABP1-dependent poly(A)-specific } \\
\text { ribonuclease subunit 2, Ubiquitin } \\
\text { specific peptidase } 52 \text { (Usp52) }\end{array}$ & NM_133992 ${ }^{\mathbf{c}}$ & $\begin{array}{l}\text { TCCTGGACTGGCCGAATTTTC } \\
\text { GGTCTAGCTCCACATTCTGTAGC }\end{array}$ & $101 \mathrm{nt}$ \\
\hline$P A R N$ & Poly $(A)$-specific ribonuclease & NM_028761 & $\begin{array}{l}\text { GCAGAGTTGGAAAAGCGGTTG }^{\mathbf{b}} \\
\text { GTGATGTAGGCATCGTACCCC }\end{array}$ & $128 \mathrm{nt}$ \\
\hline Tbp & TATA box binding protein & NM_013684 & $\begin{array}{l}\text { AGAACAATCCAGACTAGCAGCA } \\
\text { GGGAACTTCACATCACAGCTC }\end{array}$ & $120 \mathrm{nt}$ \\
\hline
\end{tabular}


A

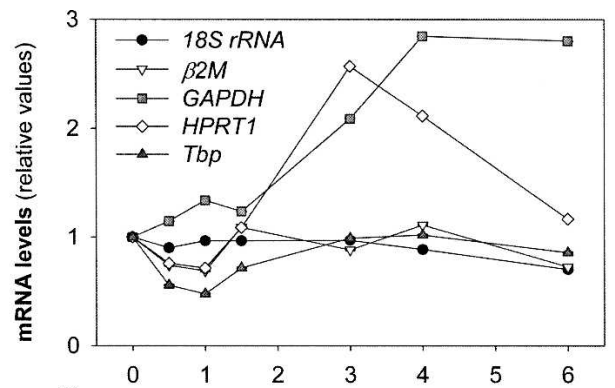

B

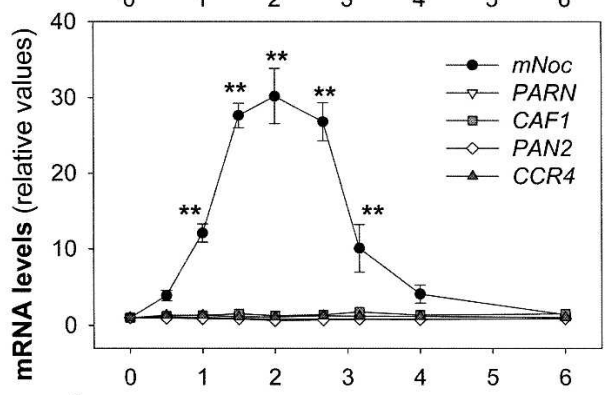

C

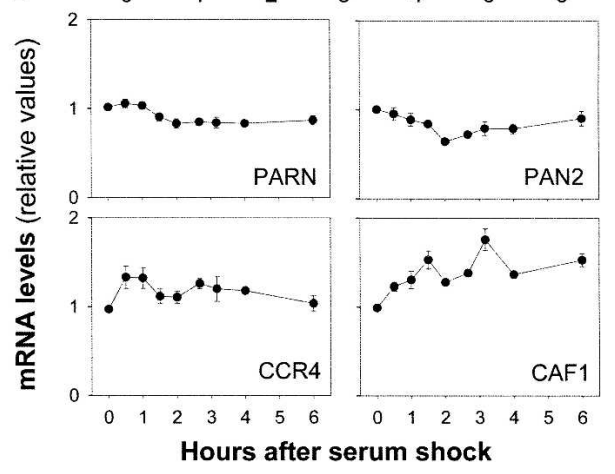

FIGURE 5. $m N o c$ is the unique deadenylase induced in serumstimulated NIH3T3 cells. Quiescent NIH3T3 cells were serum starved for $16 \mathrm{~h}$ in $0.5 \%$ FBS-DMEM, then stimulated with $50 \%$ horse serumDMEM, and after $2 \mathrm{~h}$ the medium was replaced by $0.5 \%$ FBS-DMEM. The specific mRNA levels were determined by real-time RT-PCR. (A) Analysis of potential "housekeeping" genes for data normalization. The total RNA starting quantities were similar in all time points, the data were normalized as fold change compared with $\mathrm{T}=0$. $(B)$ Effect of serum shock on five deadenylase mRNA levels. $m N o c$ transcript, but not CCR4, CAF1, PAN2, and PARN mRNAs, is induced in serumshocked NIH3T3 cells. $(C)$ The same data presented in $B$ were plotted again with a different scale to visualize changes in CCR4, CAF1, PAN2, and PARN mRNAs. In $B$ and $C$, individual data were normalized by the Pfaffl method considering $\mathrm{T}=0$ values as the calibrator, and $\beta 2 M$ as the reference gene. The graphs show the results of two independent experiments in which measurements were done by triplicate $(n=6 /$ group); values are the mean \pm SEM. Only $m$ Noc $(\mathrm{F}=42, p=5.6 \mathrm{E}-17)$ and CAF1 $(\mathrm{F}=8, p=2.4 \mathrm{E}-06)$ showed significant changes by ANOVA. $\left.{ }^{* *}\right) p<0.001$ by post hoc comparisons.

denoting that in serum-starved cells the $m N o c$ transcript levels are low.

In contrast to the acute induction of $m N o c$, the other deadenylases tested were not induced by serum shock (Fig. 5B,C). Only CAF1 message levels showed a significant increase of $50 \% 2 \mathrm{~h}$ after serum treatment. However, the magnitude of the CAF1 increment (1.5-fold) is fairly moderate compared with the $m N o c$ acute induction (30-fold).

\section{mNOC protein, but not PARN, is serum induced}

We next examined whether the mNoc mRNA acute induction is reflected by similar changes in protein levels. We raised an antibody against mNOC utilizing a recombinant truncated version of the protein (see Materials and Methods). The specificity of the antibody was examined by Western blot (Fig. 6A). The immunoreactivity of the antibody was compared in lysates of 3T3 cells and mouse embryo fibroblasts (MEFs) obtained from both $\mathrm{mNoc}^{+/+}$ and $\mathrm{mNoc}^{-1-}$ mice. We developed the $\mathrm{mNoc}^{-1-}$ mice for studies of NOC function; this animal model is being presented elsewhere (C.B. Green, N. Douris, S. Kojima, C.A. Strayer, J. Fogerty, D. Lourim, S.R. Keller, and J.C. Besharse, in prep.). The antibody recognized a unique band with an electrophoretic mobility corresponding to $\sim 42 \mathrm{kDa}$ that is present in NIH3T3 and wild-type MEF but not in serum-stimulated $\mathrm{mNoc}^{-/-}$MEF lysates. In addition, we have verified the antibody specificity in immunoblots utilizing recombinant-tagged proteins and tissues from $\mathrm{mNoc}^{-1-}$ versus wild-type mouse (data not shown).
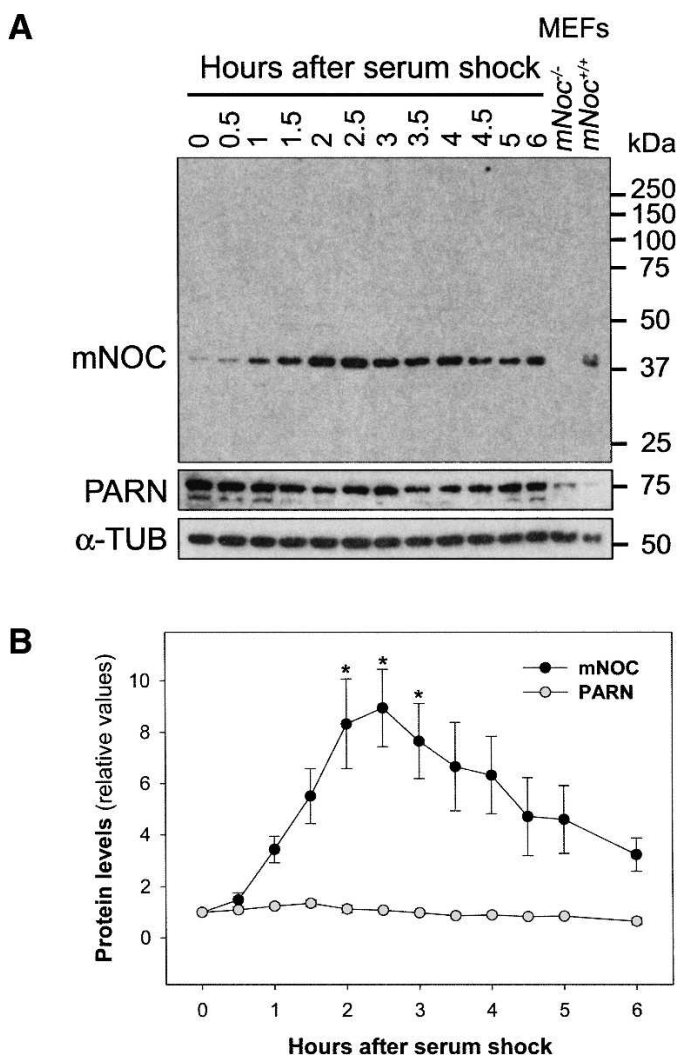

FIGURE 6. mNOC protein induction by serum shock. (A) Western blot showing the temporal profile of the $\mathrm{mNOC}$ and PARN protein levels after a serum shock. Cells were treated as in Fig 5. The lanes containing lysates of mouse embryo fibroblasts (MEFs) obtained from $\mathrm{mNoc}^{+/+}$and $\mathrm{mNoc}^{-/-}$mice serve as positive and negative controls. MEFs were serum stimulated for $2 \mathrm{~h}$. In the lower panel, an immunoblot of the same membrane using $\alpha$-tubulin antiserum as a loading control. $(B)$ The results of three blots were quantified with the Scion Image software; the graph shows the mean \pm SEM. $\left(^{*}\right) p<0.05$. 
The mNOC protein levels in serum-stimulated NIH3T3 cells increased approximately ninefold compared with the nonstimulated control (Fig. 6). The mNOC temporal profile resembles the mRNA response shown in Figures 2 and 5B. The mRNA peak ( $2 \mathrm{~h}$ after serum stimulation, Fig. 5B) precedes the highest levels of protein $(2.5 \mathrm{~h}$ after serum shock) by $\sim 30 \mathrm{~min}$. The increase in mRNA levels was 30 -fold versus ninefold for the protein (cf. Figs. 5 and 6, which used the same stimulation paradigm). The levels of mNOC protein begin to decline after $2.5 \mathrm{~h}$, indicating that it has a short half-life and that in the absence of stimulation its levels are low.

We also measured the levels of PARN protein in the same lysates of serum-stimulated NIH3T3 (Fig. 6). The relative values of this deadenylase showed a weak diminution but did not change significantly after the serum shock.

\section{DISCUSSION}

This paper reports an acute induction of the deadenylase mNOC as a cellular response to two different stimuli. This induction showed the typical characteristics of an immediate early gene response. $\mathrm{mNOC}$ was the unique polyA-specific ribonuclease induced by serum among the five described in the mouse. This suggests that mNOC plays an important role triggering the degradation and/or silencing of mRNAs of genes that are turned off under the paradigm studied.

\section{mNOC deadenylase activity}

The high similarity between the mNOC C terminus and the catalytic domain of CCR4, as well as the demonstration that $\mathrm{XNOC}$ is a deadenylase, strongly suggested that mNOC was also a polyA-specific ribonuclease (Green and Besharse 1996a; Dupressoir et al. 1999, 2001; Wang et al. 2001; Baggs and Green 2003); however, this hypothesis had not been verified until this study (Fig. 1). Although our results demonstrate that mNOC has specific deadenylase activity, the in vitro activity of GST-mNOC is weak compared with $\mathrm{xPARN}-\mathrm{His}$, as reflected in the fraction of substrate that remains adenylated. This is also true for xNOC (Baggs and Green 2003). Taking into account that we assayed a recombinant protein in vitro, many facts could explain the modest enzymatic activity: (1) we have not identified the optimal conditions; (2) the recombinant protein does not have the proper conformation or post-translational modifications; (3) it has very specific targets, and thus is not efficient at degrading generic substrates; and (4) it may require other interacting proteins, a particular cellular environment, and/or modifications produced after a specific event (e.g., serum or TPA induction).

\section{mNoc induction}

Noc was originally identified by virtue of its rhythmic mRNA profiles; we have previously shown that circadian clocks control Noc mRNA and protein expression in Xenopus retina (Green and Besharse 1996a; Liu and Green 2001, 2002; Baggs and Green 2003). Likewise, in mouse, Noc shows a high-amplitude mRNA content rhythm in a wide range of tissues (Wang et al. 2001; Barbot et al. 2002). Here, we show that extracellular factors also modulate $m N o c$ expression through an acute induction. Serum and TPA-but not forskolin or dexamethasone-induced $m N o c$ levels (Figs. 2, 5, 6). The increase in the transcript levels generated by TPA was not dependent on protein synthesis (Fig. 3), and the half-life of the induced message is short (Fig. 4), a requisite to obtain a transient response. These results support our conclusion that $m N o c$ is an IEG. Since extracellular signals modulate expression programs, it is reasonable that in addition to transcription factors, mRNA decay-promoting factors also participate in the immediate early response.

Addition of CHX protected $m$ Noc mRNA from degradation (Fig. 4). This is consistent with previous reports showing that inhibition of translation stabilizes many mRNAs (Jacobson and Peltz 1996). Since the effect of $\mathrm{CHX}$ on $m N o c$ is so dramatic (Fig. 3), we cannot rule out the possibility that $\mathrm{CHX}$ inhibits the synthesis of factors normally involved in $m N o c$ mRNA degradation and/or transcriptional repression following the induction.

The mechanism involved in the $m N o c$ induction is not clear since the stimuli utilized activate numerous signaling pathways. Serum, TPA, forskolin, and dexamethasone were tested due to their capacity to entrain circadian clocks in mammalian fibroblast cultures (Balsalobre et al. 1998, 2000; Akashi and Nishida 2000; Yagita and Okamura 2000; Yagita et al. 2001; Nagoshi et al. 2004). The mechanism by which these factors synchronize molecular oscillators is thought to be through the immediate early activation of the clock gene Per1. Although $m N o c$ and $m P e r 1$ have similar TPA-induction profiles, $m N o c$ was not activated by forskolin or dexamethasone. Thus, it is clear that mPer1 induction and/or resetting of circadian clocks are not sufficient for stimulation of $m N o c$ expression. Moreover, mNoc induction by TPA does not require protein synthesis, indicating that it does not require the induction of any clock protein (components of the intracellular molecular clock mechanism). These experiments also show that $m N o c$ induction is not required for the synchronization of circadian gene expression triggered by forskolin and dexamethasone.

Circadian gene expression is modulated through various mechanisms (for review, see Reppert and Weaver 2002; Schibler et al. 2003; Lowrey and Takahashi 2004). The central clock mechanism consists of transcription factors or regulators that rhythmically activate the transcription of some circadian clock controlled genes ( $c c g s)$. A number of these direct target genes are also transcription factors that in turn regulate the cyclic expression of indirect $c c g s$. In addition, in multicellular organisms, the circadian system regulates the secretion of a number of hormones and 
humoral factors, activity and feeding behaviors, as well as body temperature, among other variables. As a consequence, many systemic physiological signals display daily oscillations (Schibler et al. 2003). This raises the question of whether rhythmic $m$ Noc expression in vivo is the result of a daily acute induction through a systemic circadian signal that triggers its expression in different tissues, as opposed to cell-autonomous control by the intracellular clockwork. The fact that the cellular oscillator does not mediate the acute response of $m N o c$ to extracellular stimuli (see above) suggests that some rhythmic systemic signals may directly induce $m N o c$ expression in vivo. This hypothesis could explain why the phase of $m N o c$ expression in different tissues is similar (Wang et al. 2001) despite the fact that central clock genes show phase differences among those same tissues. This idea is also supported by recent work demonstrating that in transgenic mice with liver-specific loss of circadian clock function (but with the other body clocks intact), $m$ Noc is one of the few mRNAs that continue to exhibit rhythmic expression in the liver, suggesting that it can be driven from systemic rhythmic signals (Kornmann et al. 2007).

\section{$m$ Noc transcript is the unique deadenylase mRNA induced by serum}

Among the five deadenylases described in mouse, $m$ Noc message was the only one induced by serum stimulation (Fig. 5). Taking into account that deadenylation is considered to be the event that triggers the degradation of the majority of transcripts (Cao and Parker 2001; Wang et al. 2002), our results suggest an important role for mNOC in the destabilization of mRNAs that decay under these conditions.

The fates of specific mRNAs are known to be modulated by extracellular signals. This is produced by post-transcriptional modifications, relocalization to different cellular compartments, and/or expression rate changes of the factors interacting with messages (Shim and Karin 2002; Wilusz and Wilusz 2004). Several reports have shown the stabilization of specific transcripts-including proto-oncogenes, cytokine, and chemokine genes-following cell stimulation (Shim and Karin 2002; Dean et al. 2004; Briata et al. 2005, and references therein). In contrast, we are not aware of any previous study showing transcript destabilization, or activation of mRNA decay-promoting factors, by serum or TPA stimulation.

PAN2 and CCR4 were recently proposed to be the major polyA nucleases responsible for cytoplasmic deadenylation in NIH3T3 cultures (Yamashita et al. 2005). This statement is supported by experiments conducted in proliferating and nonstimulated cells. Our results suggest that in confluent cultures, where proliferation is inhibited, and after a serum or TPA stimulation, $\mathrm{mNOC}$ is a major deadenylase. Since we have not determined the specific activity of each deadenylase, further studies will be needed to directly demonstrate this. It is important to consider that whereas some transcripts increase their half-life in response to an external stimulus simultaneously, others are destabilized or are just transiently stabilized (for example, IEGs). In other words, regulation of stability is likely different for different sets of mRNAs, and the ability of different deadenylases to act on different message populations or in different physiological situations could be an important point of regulation in this process. During the last few years, many factors (cis- and trans-acting elements) have been identified, including even new cytoplasmic subdomains involved in mRNA surveillance. However, we still do not understand how mRNA stability is controlled in different cells/tissues under diverse physiological conditions. The elucidation of this complex regulation may help give a better understanding of gene expression and some diseases including cancer, chronic inflammatory responses, and coronary disease (Wilusz et al. 2001).

In summary, our studies have been focused on understanding the specific function of a deadenylase, a factor involved in triggering mRNA degradation or silencing (Baggs and Green 2006). We have shown that mouse $m$ Noc is expressed under circadian control in numerous tissues during the early night (Wang et al. 2001) and that it is acutely induced by extracellular stimulation (this report). These two characteristics differentiate mNOC from the other deadenylases, suggesting that it has specific mRNA targets and/or it is active only during specific time windows or physiological conditions.

\section{MATERIALS AND METHODS}

\section{DNA plasmids and protein purification}

Mouse Noc (GenBank Accession Number AF199491) and Cry2 (AF156987) were cloned in a pDEST15 vector (Invitrogen) for Escherichia coli expression with an N-terminal GST-tag. The predicted $m N o c \mathrm{Mg}^{2+}$-binding (D193A) mutant was generated by site-directed mutagenesis (QuikChange kit, Stratagene) on the pDEST15-mNoc plasmid DNA.

BL21 cells were transformed with the expression plasmids, and induced and homogenized in lysis buffer $(20 \mathrm{mM}$ HEPES $\mathrm{pH}$ 8; $150 \mathrm{mM} \mathrm{NaOAc}, 1 \mathrm{mM} \mathrm{MgOAc}, 10 \mathrm{mM}$ KOAc) containing $0.2 \mu \mathrm{g} / \mathrm{mL}$ lysozyme, $5 \mu \mathrm{g} / \mathrm{mL}$ DNase I, $1 \%$ Triton X-100, and protease inhibitors. The lysates were clarified by centrifugation $(34,000 \mathrm{RFC}, 20 \mathrm{~min})$, and $10 \%$ glycerol was added to the supernatant. The protein was affinity purified with Glutathione Sepharose (Amersham). The column was washed $2 \times$ with lysis buffer containing $0.5 \%$ Triton X-100 and $10 \%$ glycerol, $3 \times$ with wash buffer (100 mM Tris-OAc pH 8, $150 \mathrm{mM}$ KOAc, $0.05 \%$ igepal, $0.01 \%$ SDS, $20 \%$ glycerol, and $1 \mathrm{mM} \mathrm{DTT}), 2 \times$ with storage buffer (50 mM HEPES pH 8, $0.01 \mathrm{mM} \mathrm{MgOAc,} 20 \mathrm{mM}$ KOAc, $20 \%$ glycerol, and $0.1 \%$ igepal), and stored at $4^{\circ} \mathrm{C}$ in this buffer containing protease inhibitors. Xenopus PARN was the only protein expressed with a different vector (His-tagged) and that 
was eluted from the affinity resin. It was produced and purified as described (Copeland and Wormington 2001; Baggs and Green 2003). The proteins linked to Sepharose and xPARN-His were analyzed by SDS-PAGE followed by silver staining, and the concentration was estimated by running a BSA standard curve in the same gel. The band densities were calculated with Scion Image software.

\section{Deadenylase assay}

The deadenylase assay was carried out as described previously (Copeland and Wormington 2001; Baggs and Green 2003) with modifications inspired by Viswanathan and coworkers (2003). The RNA substrate was synthesized from the G52 plasmid containing the last $86 \mathrm{nt}$ of the globin $3^{\prime}$ UTR followed by a 100-nt polyA tail. A radiolabeled RNA substrate was synthesized by transcribing BamHI-linearized DNA constructs with SP6 polymerase (GIBCO-BRL) in the presence of $\left(\alpha-{ }^{32} \mathrm{P}\right)$-UTP $(800 \mathrm{Ci} / \mathrm{mmol}$, NEN) and $625 \mu \mathrm{M}$ of a $5^{\prime}$ GpppG cap analog (Amersham Pharmacia Biotech). Resulting RNA products were separated on $6 \%$ polyacrylamide/7 $\mathrm{M}$ urea gels and eluted in TNES buffer (0.1 M Tris- $\mathrm{HCl} \mathrm{pH}$ 7.5, 0.3 M NaCl, 0.01 M EDTA, 2\% w/v SDS) overnight at room temperature. Purified RNA $\left(1 \times 10^{5} \mathrm{cpm}\right.$, $\sim 1.5 \mathrm{ng}$ ) was incubated with the GST-recombinant proteins (500 ng) linked to sepharose in reaction buffer $(50 \mathrm{mM}$ HEPES-NaOH $\mathrm{pH} \mathrm{8,} 0.01 \mathrm{mM} \mathrm{MgOAc}, 20 \mathrm{mM} \mathrm{KOAc}$ ) for $30 \mathrm{~min}$ (or the indicated times) at $37^{\circ} \mathrm{C}$ in the presence of $5 \mathrm{U}$ of RNase Block (Stratagene). The xPARN-His protein assay conditions were identical to that described previously with no modifications (Copeland and Wormington 2001; Baggs and Green 2003). The reaction was stopped by the addition of formamide and heating for $5 \mathrm{~min}$ at $85^{\circ} \mathrm{C}$. The products were separated on $6 \%$ polyacrylamide/7 $\mathrm{M}$ urea gels and revealed by autoradiography. The RNA substrate and deadenylated product were identified by comparing their electrophoretic mobility with the enzyme blank and RNase $\mathrm{H}$ (Invitrogen)-treated substrate in the presence of oligo(dT), respectively. Alternatively, the reaction products were analyzed by TLC in PEI cellulose plates (Sigma), and developed in 15:1:10 isobutyric acid: $\mathrm{NH}_{4} \mathrm{OH}: \mathrm{H}_{2} \mathrm{O}$ as described by Copeland and Wormington (2001).

\section{Cell cultures}

$\mathrm{NIH} /$ Swiss $3 \mathrm{~T} 3$ fibroblasts (ATCC) were grown at $37^{\circ} \mathrm{C}$, under $5 \%$ $\mathrm{CO}_{2}$ and $95 \%$ air, in Dulbecco's Modified Eagle Medium (DMEM, Gibco) supplemented with $10 \%$ fetal bovine serum (FBS, Gibco). Experiments were done 48-72 h after cultures reached confluence. Serum starvation was initiated $16-48 \mathrm{~h}$ before the experiment by replacing the DMEM containing 10\% FBS with DMEM containing either $1 \%$ or $0.5 \%$ FBS as specified.

Serum shock: At $\mathrm{T}=0$ (nonstimulated cells), medium was exchanged for prewarmed 50\% FBS or horse serum (Gibco)DMEM. After $2 \mathrm{~h}$ of incubation, the medium was replaced with either $1 \%$ or $0.5 \%$ FBS-DMEM (modified from Balsalobre et al. 1998; Nagoshi et al. 2004). TPA: The phorbol ester 12-Otetradecanoyl phorbol 13-acetate (Sigma, stock $1 \mathrm{mM}$ in DMSO) was diluted to $2.5 \mu \mathrm{M}$ in medium and added to the cultures to a final concentration of $100 \mathrm{nM}$ (modified from Akashi and Nishida 2000). Forskolin and dexamethasone were added to a final concentration of $10 \mu \mathrm{M}$ and $100 \mathrm{nM}$, respectively; $15 \mathrm{~min}$ later, the medium was replaced by 1\% FBS-DMEM (modified from Balsalobre et al. 2000; Yagita and Okamura 2000). Cycloheximide (CHX, $10 \mu \mathrm{M}$, Sigma) was added $1 \mathrm{~h}$ before cell stimulation, and actinomycin D ( $1 \mu \mathrm{g} / \mathrm{mL}$, Sigma) $2 \mathrm{~h}$ after TPA induction. Cells were washed in PBS and harvested at the indicated times after stimulation in TRIzol reagent (Invitrogen) for RNA extraction, or in lysis buffer (T-PER, Pierce) containing $2 \mathrm{mM}$ DTT, $1 \mathrm{mM}$ EDTA, and protease inhibitor cocktail (Sigma) for protein analysis.

\section{RNA isolation and cDNA synthesis}

Total RNA was purified using TRIzol reagent according to the manufacturer's instructions (Invitrogen). One microgram of total RNA was utilized as a template for the cDNA synthesis reaction using iScript reverse transcriptase and a blend of oligo (dT) and random hexamers in a final volume of $20 \mu \mathrm{L}$ (iScript cDNA synthesis kit, Bio-Rad).

\section{Northern blot}

Northern blots were done as described (Green and Besharse 1996b). Briefly, $10 \mu \mathrm{g}$ of total RNA was separated by electrophoresis in a $1 \%$ agarose formaldehyde gel and transferred to BrightStar membranes (Ambion). Membranes were hybridized utilizing ULTRAhyb hybridization buffer (Ambion) according to the manufacturer's instructions with a $5 \times 10^{5} \mathrm{cpm} / \mathrm{mL}$ probe for $16 \mathrm{~h}$ at $45^{\circ} \mathrm{C}$. The probe was synthesized by PCR in the presence of $\left(\alpha-{ }^{32} \mathrm{P}\right)$-dCTP (NEN) utilizing the primers: $5^{\prime}$-AACCATGCAGG TACAGTCT-3' and 5'-GTTTGGAAGAGGCTTCAAC-3', and plasmid DNA containing the $m N o c$ sequence as a template. The probe was purified with the DyeEx Spin kit (Qiagen). Membranes were washed two times with $1 \times$ SSC, $0.1 \%$ SDS for $15 \mathrm{~min}$ at $50^{\circ} \mathrm{C}$, and then two more times with $0.1 \times$ SSC, $0.5 \%$ SDS for $15 \mathrm{~min}$ at $50^{\circ} \mathrm{C}$. The hybridization signal was quantified utilizing a Storm PhosphorImager system (Molecular Dynamics) followed by densitometric analysis using an imaging program. Values were normalized by densitometric values for the $28 \mathrm{~S}$ rRNA band stained with methylene blue. Transcript size was determined using Perfect RNA markers (Novagen).

\section{Real-time quantitative PCR}

The primers utilized for real-time quantitative PCR (Invitrogen) are listed in Table 1. The sequences were taken from the Harvard Primer Bank (Wang and Seed 2003) except for the 18S rRNA primer pair that was reported by Yamamoto et al. (2005). The quantification was performed in a MyiQ single-color real-time PCR detection system (Bio-Rad). The amplification mix contained $1 \mu \mathrm{L}$ of the cDNA synthesis reaction, $0.8 \mu \mathrm{M}$ of each primer, and $12.5 \mu \mathrm{L}$ of iQ SYBR green supermix (Bio-Rad) in a total volume of $25 \mu \mathrm{L}$. The cycling conditions were $30 \mathrm{sec}$ polymerase activation at $95.0^{\circ} \mathrm{C}$, and 40 cycles of $95.0^{\circ} \mathrm{C}$ for $30 \mathrm{sec}, 60.0^{\circ} \mathrm{C}$ for $30 \mathrm{sec}$, and $72.0^{\circ} \mathrm{C}$ for $30 \mathrm{sec}$. Each assay included a standard curve in duplicate, utilizing 1:5 serial dilutions of cDNA from $2 \mathrm{~h}$ serum-stimulated cells. Samples were measured in triplicate. The PCR product was checked by melt curve analysis, and the standard curve linearity and PCR efficiency were optimized. For housekeeping genes (Fig. 6A), the relative RNA starting quantities generated by the Optical system software 
(Bio-Rad) were normalized setting the nonstimulated cells $(\mathrm{T}=0)$ equal to 1. For the deadenylases (Fig. 6B,C), the data were normalized by the Pfaffl method (Real-Time PCR Applications Guide, Bio-Rad):

$$
\text { Ratio }=\frac{\left(\mathrm{E}_{\text {target }}\right)^{\left.\Delta \mathrm{C}_{\mathrm{T}}, \text { target(calibrator - test }\right)}}{\left(\mathrm{E}_{\mathrm{ref}}\right)^{\left.\Delta \mathrm{C}_{\mathrm{T}}, \text { ref (calibrator - test }\right)}}
$$

where E represents PCR efficiency; Ref represents $\beta 2$-microglobulin; calibrator represents no stimulated cells; and $\mathrm{C}_{\mathrm{T}}$ represents the threshold cycle.

\section{Western blotting}

Protein lysates $(5 \mu \mathrm{g})$ were separated in $10 \%$ SDS polyacrylamide gels and transferred to PVDF membranes (Bio-Rad) using standard protocols for Western blotting. We developed an antibody for mNOC detection. The DNA sequence coding for amino acids A152-F429 of mNOC (GenBank Accession Number AF199491) was cloned in a pDEST17 vector (Invitrogen) and expressed in bacteria. The $6 \times$ His-tagged recombinant protein was affinity purified using His-Bind resin according to the manufacturer's instructions (Novagen). This recombinant protein was utilized as an immunogen to raise an antibody in chickens (Covance). Sera and total egg IgY were affinity purified using recombinant GST-NOC following a protocol from Bar-Peled and Raikhel (1996). The anti-PARN antibody (Korner et al. 1998) was generously provided by Michael Wormington (University of Virginia). A mouse monoclonal anti-alpha tubulin antibody (Sigma) was utilized for tubulin detection. The secondary antibodies were HRP conjugated, and the detection was done utilizing a chemiluminescent system (Roche). The signal was quantified by Scion Image software.

\section{Statistical analysis}

Statistical analyses involved analysis of variance (ANOVA) with Newman-Keuls post hoc tests when appropriate.

\section{ACKNOWLEDGMENTS}

We thank Mike Wormington (University of Virginia) for helpful discussion, criticism of the manuscript, and for providing the PARN antibody and plasmid. This work was supported by NIH Grants EY11489 (C.B.G.), GM076626 (C.B.G.), and EY02414 (J.C.B.), and Development Funds from the Medical College of Wisconsin (J.C.B.).

Received August 29, 2006; accepted February 12, 2007.

\section{REFERENCES}

Akashi, M. and Nishida, E. 2000. Involvement of the MAP kinase cascade in resetting of the mammalian circadian clock. Genes \& Dev. 14: 645-649.

Baggs, J.E. and Green, C.B. 2003. Nocturnin, a deadenylase in Xenopus laevis retina: A mechanism for post-transcriptional control of circadian-related mRNA. Curr. Biol. 13: 189-198.

Baggs, J.E. and Green, C.B. 2006. Functional analysis of nocturnin: A circadian clock-regulated gene identified by differential display. Methods Mol. Biol. 317: 243-254.
Balsalobre, A., Damiola, F., and Schibler, U. 1998. A serum shock induces circadian gene expression in mammalian tissue culture cells. Cell 93: 929-937.

Balsalobre, A., Marcacci, L., and Schibler, U. 2000. Multiple signaling pathways elicit circadian gene expression in cultured Rat-1 fibroblasts. Curr. Biol. 10: 1291-1294.

Barbot, W., Wasowicz, M., Dupressoir, A., Versaux-Botteri, C., and Heidmann, T. 2002. A murine gene with circadian expression revealed by transposon insertion: Self-sustained rhythmicity in the liver and the photoreceptors. Biochim. Biophys. Acta 1576: 81-91.

Bar-Peled, M. and Raikhel, N.V. 1996. A method for isolation and purification of specific antibodies to a protein fused to the GST. Anal. Biochem. 241: 140-142.

Briata, P., Forcales, S.V., Ponassi, M., Corte, G., Chen, C.Y., Karin, M., Puri, P.L., and Gherzi, R. 2005. p38-dependent phosphorylation of the mRNA decay-promoting factor KSRP controls the stability of select myogenic transcripts. Mol. Cell 20: 891-903.

Cao, D. and Parker, R. 2001. Computational modeling of eukaryotic mRNA turnover. RNA 7: 1192-1212.

Chen, J., Chiang, Y.C., and Denis, C.L. 2002. CCR4, a 3'-5' poly(A) RNA and ssDNA exonuclease, is the catalytic component of the cytoplasmic deadenylase. EMBO J. 21: 1414-1426.

Copeland, P.R. and Wormington, M. 2001. The mechanism and regulation of deadenylation: Identification and characterization of Xenopus PARN. RNA 7: 875-886.

Dean, J.L., Sully, G., Clark, A.R., and Saklatvala, J. 2004. The involvement of AU-rich element-binding proteins in p38 mitogenactivated protein kinase pathway-mediated mRNA stabilization. Cell. Signal. 16: 1113-1121.

Dlakic, M. 2000. Functionally unrelated signalling proteins contain a fold similar to $\mathrm{Mg}^{2+}$-dependent endonucleases. Trends Biochem. Sci. 25: 272-273.

Dupressoir, A., Barbot, W., Loireau, M.P., and Heidmann, T. 1999. Characterization of a mammalian gene related to the yeast CCR4 general transcription factor and revealed by transposon insertion. J. Biol. Chem. 274: 31068-31075.

Dupressoir, A., Morel, A.P., Barbot, W., Loireau, M.P., Corbo, L., and Heidmann, T. 2001. Identification of four families of yCCR4- and $\mathrm{Mg}^{2+}$-dependent endonuclease-related proteins in higher eukaryotes, and characterization of orthologs of yCCR4 with a conserved leucine-rich repeat essential for hCAF1/hPOP2 binding. BMC Genomics 2: 9.

Green, C.B. and Besharse, J.C. 1996a. Identification of a novel vertebrate circadian clock-regulated gene encoding the protein nocturnin. Proc. Natl. Acad. Sci. 93: 14884-14888.

Green, C.B. and Besharse, J.C. 1996b. Use of a high-stringency differential display screen for identification of retinal mRNAs that are regulated by a circadian clock. Brain Res. 37: 157-165.

Jacobson, A. and Peltz, S.W. 1996. Interrelationships of the pathways of mRNA decay and translation in eukaryotic cells. Annu. Rev. Biochem. 65: 693-739.

Korner, C.G. and Wahle, E. 1997. Poly(A) tail shortening by a mammalian poly(A)-specific 3 '-exoribonuclease. J. Biol. Chem. 272: $10448-10456$.

Korner, C.G., Wormington, M., Muckenthaler, M., Schneider, S., Dehlin, E., and Wahle, E. 1998. The deadenylating nuclease (DAN) is involved in poly(A) tail removal during the meiotic maturation of Xenopus oocytes. EMBO J. 17: 5427-5437.

Kornmann, B., Schaad, O., Bujard, H., Takahashi, J.S., and Schibler, U. 2007. System-driven and oscillator-dependent circadian transcription in mice with a conditionally active liver clock. PLoS Biol. 5: 1-11.

Liu, X. and Green, C.B. 2001. A novel promoter element, photoreceptor conserved element II, directs photoreceptor-specific expression of nocturnin in Xenopus laevis. J. Biol. Chem. 276: $15146-15154$.

Liu, X. and Green, C.B. 2002. Circadian regulation of nocturnin transcription by phosphorylated CREB in Xenopus retinal photoreceptor cells. Mol. Cell. Biol. 22: 7501-7511. 
Lowrey, P.L. and Takahashi, J.S. 2004. Mammalian circadian biology: Elucidating genome-wide levels of temporal organization. Annu. Rev. Genomics Hum. Genet. 5: 407-441.

Marquez, S., Crespo, P., Carlini, V., Garbarino-Pico, E., Baler, R., Caputto, B.L., and Guido, M.E. 2004. The metabolism of phospholipids oscillates rhythmically in cultures of fibroblasts and is regulated by the clock protein PERIOD 1. FASEB J. 18: 519-521.

Nagoshi, E., Saini, C., Bauer, C., Laroche, T., Naef, F., and Schibler, U. 2004. Circadian gene expression in individual fibroblasts: Cellautonomous and self-sustained oscillators pass time to daughter cells. Cell 119: 693-705.

Nagoshi, E., Brown, S.A., Dibner, C., Kornmann, B., and Schibler, U. 2005. Circadian gene expression in cultured cells. Methods Enzymol. 393: 543-557.

Parker, R. and Song, H. 2004. The enzymes and control of eukaryotic mRNA turnover. Nat. Struct. Mol. Biol. 11: 121-127.

Pittendrigh, C.S. 1993. Temporal organization: Reflections of a Darwinian clock watcher. Annu. Rev. Physiol. 55: 16-54.

Reppert, S.M. and Weaver, D.R. 2002. Coordination of circadian timing in mammals. Nature 418: 935-941.

Schibler, U., Ripperger, J., and Brown, S.A. 2003. Peripheral circadian oscillators in mammals: Time and food. J. Biol. Rhythms 18: 250260.

Schmittgen, T.D. and Zakrajsek, B.A. 2000. Effect of experimental treatment on housekeeping gene expression: Validation by realtime, quantitative RT-PCR. J. Biochem. Biophys. Methods 46: 69-81.

Shim, J. and Karin, M. 2002. The control of mRNA stability in response to extracellular stimuli. Mol. Cells 14: 323-331.

Uchida, N., Hoshino, S., and Katada, T. 2004. Identification of a human cytoplasmic poly(A) nuclease complex stimulated by poly(A)-binding protein. J. Biol. Chem. 279: 1383-1391.

Vandesompele, J., De Preter, K., Pattyn, F., Poppe, B., Van Roy, N., De Paepe, A., and Speleman, F. 2002. Accurate normalization of real-time quantitative RT-PCR data by geometric averaging of multiple internal control genes. Genome Biol. 3: RESEARCH0034.

Viswanathan, P., Chen, J., Chiang, Y.C., and Denis, C.L. 2003. Identification of multiple RNA features that influence CCR4 deadenylation activity. J. Biol. Chem. 278: 14949-14955.
Viswanathan, P., Ohn, T., Chiang, Y.C., Chen, J., and Denis, C.L. 2004. Mouse CAF1 can function as a processive deadenylase $/ 3^{\prime}-5^{\prime}-$ exonuclease in vitro but in yeast the deadenylase function of CAF1 is not required for mRNA poly(A) removal. J. Biol. Chem. 279: 23988-23995.

Wang, X. and Seed, B. 2003. A PCR primer bank for quantitative gene expression analysis. Nucleic Acids Res. 31: e154.

Wang, Y., Osterbur, D.L., Megaw, P.L., Tosini, G., Fukuhara, C., Green, C.B., and Besharse, J.C. 2001. Rhythmic expression of Nocturnin mRNA in multiple tissues of the mouse. BMC Dev. Biol. 1: 9.

Wang, Y., Liu, C.L., Storey, J.D., Tibshirani, R.J., Herschlag, D., and Brown, P.O. 2002. Precision and functional specificity in mRNA decay. Proc. Natl. Acad. Sci. 99: 5860-5865.

Welsh, D.K., Yoo, S.H., Liu, A.C., Takahashi, J.S., and Kay, S.A. 2004. Bioluminescence imaging of individual fibroblasts reveals persistent, independently phased circadian rhythms of clock gene expression. Curr. Biol. 14: 2289-2295.

Wilusz, C.J. and Wilusz, J. 2004. Bringing the role of mRNA decay in the control of gene expression into focus. Trends Genet. 20: 491-497.

Wilusz, C.J., Wormington, M., and Peltz, S.W. 2001. The cap-to-tail guide to mRNA turnover. Nat. Rev. Mol. Cell Biol. 2: 237-246.

Yagita, K. and Okamura, H. 2000. Forskolin induces circadian gene expression of rPer1, rPer2 and $\mathrm{dbp}$ in mammalian rat-1 fibroblasts. FEBS Lett. 465: 79-82.

Yagita, K., Tamanini, F., van Der Horst, G.T., and Okamura, H. 2001. Molecular mechanisms of the biological clock in cultured fibroblasts. Science 292: 278-281.

Yamamoto, T., Nakahata, Y., Tanaka, M., Yoshida, M., Soma, H., Shinohara, K., Yasuda, A., Mamine, T., and Takumi, T. 2005. Acute physical stress elevates mouse period 1 mRNA expression in mouse peripheral tissues via a glucocorticoid-responsive element. J. Biol. Chem. 280: 42036-42043.

Yamashita, A., Chang, T.C., Yamashita, Y., Zhu, W., Zhong, Z., Chen, C.Y., and Shyu, A.B. 2005. Concerted action of poly(A) nucleases and decapping enzyme in mammalian mRNA turnover. Nat. Struct. Mol. Biol. 12: 1054-1063. 

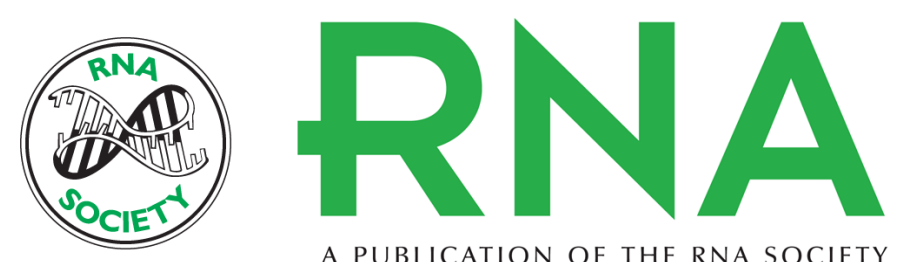

A PUBLICATION OF THE RNA SOCIETY

\section{Immediate early response of the circadian polyA ribonuclease nocturnin to two extracellular stimuli}

Eduardo Garbarino-Pico, Shuang Niu, Mark D. Rollag, et al.

RNA 2007 13: 745-755 originally published online March 30, 2007

Access the most recent version at doi:10.1261/rna.286507

\section{References This article cites 46 articles, 16 of which can be accessed free at: http://rnajournal.cshlp.org/content/13/5/745.full.html\#ref-list-1}

License Email Alerting $\begin{aligned} & \text { Receive free email alerts when new articles cite this article - sign up in the box at the } \\ & \text { Service }\end{aligned}$ top right corner of the article or click here.

To subscribe to $R N A$ go to:

http://rnajournal.cshlp.org/subscriptions 